\title{
Learning Mathematics in an Authentic Mobile Environment: The Perceptions of Students
}

\author{
$\underline{\text { doi:10.3991/ijim.v3s1.813 }}$ \\ N. Baya'a and W. Daher \\ ${ }^{1}$ Al-Qasemi Academic College of Education, Baqa El-Garbiah, Israel
}

\begin{abstract}
This research reports an experiment which took place in an Arab middle school in Israel. The experiment was led by three pre-service teachers who were carrying out their final project in the field of teaching mathematics using mobile phones. The pre-service teachers worked with 32 eighth grade students to carry out authentic real life outdoor activities in the nature. We used discourse analysis and grounded theory to analyze the perceptions of the students regarding their mathematics learning using mobile phones. We found that the novelty of the experiment and the use of mobile phones in mathematics learning were the main characteristics perceived by the students as influencing their decision to join the experiment. Furthermore, the students perceived various qualities of the mathematics learning that were enabled by the use of mobile phones: (1) exploring mathematics independently (2) learning mathematics through collaboration and team work; where the collaboration is on equal terms (3) learning mathematics in a societal and humanistic environment (4) learning mathematics in authentic real life situations (5) visualizing mathematics and investigating it dynamically (6) carrying out diversified mathematical actions using new and advanced technologies (7) learning mathematics easily and efficiently. In the overall, the students were positively impressed by the potentialities and capabilities of the mobile phones used in the mathematics learning process. This indicates that mathematics education could benefit form utilizing these new technological tools.
\end{abstract}

Index Terms-Mobile learning, mathematics education, middle school students, pre-service teachers, new technologies, mobile phones, perceptions of mathematics learning.

\section{INTRODUCTION}

\section{A. Mathematics mobile education}

In spite of the burst of mobile phones in most of our daily lives aspects, the utilization of these devices in education is still new [1] and in its infancy [2]. This is true for the use of mobile phones in education in general and especially for its use in teaching mathematics. On the other hand, we are aware recently of the increasing commonness of mobile and wireless devices, especially mobile phones, amongst the young generation. This provides new possibilities, opportunities and challenges for the educational environment [3]. Furthermore, some recent studies examined the use of mobile phones in learning mathematics amongst university pre-service teachers ([4], [5]). This implies new era for mobile phone integration in the mathematics class in which the diversified mobile features are utilized to build mathematical knowledge.
Ref. [5] studied learning processes and experiences within a mobile phone learning environment. Doing so they aimed to examine how socio-cultural and situated learning aspects were reflected in these processes and experiences. They found that the contribution of the mobile phone environment "lies not only in making dynamic mathematical application more available, but also in supporting the execution of tasks that are closer to the students' experiences and more relevant to them, which has the potential to enhance experiential learning." In addition the participants' learning experiences contributed to personal learning processes, which may motivate the participant learning.

\section{B. Students' perceptions of their learning}

Ref. [6] says, "Understanding students' perceptions of accounting is an important first step in the effort to attract the best to the accounting profession." We think that understanding students' perception of mathematics learning using mobile phones is an important step to understand how to attract middle school students to learn mathematics in this new environment. This understanding would help us know what factors influence students' learning of mathematics using mobile phones and how to motivate them to do this learning successfully and with enjoyment.

Ref. [7] studied students' perceptions of online and distance learning and found that students perceive online learning to have a significant relative advantage to traditional learning. These advantages include saving their time, fitting better in their schedules, and enabling them to take more courses. The students did not believe that they learn more in online learning courses. In additions, they had some concerns related to being able to contribute to the forum discussions.

\section{Authentic learning}

Ref. [8] claims that students better understand and apply studied materials when they are engaged in real world issues and situations. Ref. [9] points out that authentic situations and scenarios provide a stimulus for students' learning and thus create greater motivation and excitement for this process. This ref. also states that representing and simulating real-world problems, provides an important context for students' thinking. Regarding the contribution of online education to authentic learning, [10] asserts that technology and online instruction can facilitate learning by providing simulation of real-life context in order to simplify and illustrate it for the learners who face solving complex authentic problems. Regarding using mobile devices in authentic learning, [11] declares that mobile devices extend the learning environment in which the students work, and integrate it in real life situations where 
learning can occur in authentic contexts. Ref. [12] says, "Mobile learning can guide a learner to an authentic learning context and incorporate the field objects with closely related information in the handheld device to initiate the process of knowledge acquisition." In our research, we want to study the students' perceptions of mathematics learning when their knowledge acquisition is initiated by authentic activities during which they use mobile phone features in real-life situations.

Little research has been done regarding students' mathematical learning using mobile phones, especially research that involves middle school students. Our research aims to understand how middle school students perceive such learning.

\section{Research questions}

- What characteristics of the mobile phone environment do middle school students perceive as important for their positive decision to join an experiment involving mathematics learning using mobile phones?

- What characteristics of the mobile phone environment do middle school students perceive during and after they learn mathematics in authentic learning context using mobile phones?

- What qualities of mathematics learning do students perceive as being enabled by the use of the mobile phones in the learning process?

\section{RESEARCH Methodology}

\section{A. Research setting}

The experiment took place in an Arab middle school in the city of Umelfahm in Israel, and was led by three preservice teachers who were carrying out their final project in the field of teaching mathematics using mobile phones. This project was part of their tasks in a mathematics didactics seminar. The pre-service teachers selected 32 eighth grade students to participate in the experiment. The selection was done based on the interest of the students and the ownership of appropriate cellular phone. The learning was done by carrying out outdoor activities that involved exploring and investigating mathematics concepts and relations of real-life phenomena. The students utilized various features and qualities of the mobile phone to do such exploration and investigation.

The students used mathematical midlets from the site of the Institute for Alternatives in Education that operates within the Faculty of Education at the University of Haifa, Israel: www.math4mobile.com. These midlets support the learning of algebra and geometry. In our experiment, the students used the algebraic midlets that enabled them to see the graphs of several templates of linear functions. They could see the change in the corresponding straight line as the result of changing parameters in the algebraic form. They also had the opportunity to set points in a coordinate system and to check if a straight line could connect all of them; indicating a linear relation in the reallife phenomenon.

Carrying out the activities the students exploited the mobility, dynamics, availability and accessibility properties of the cellular phones and used various tools and technologies embedded in them, such as: taking pictures, recording video, recording audio, measuring time, transferring of information, voice and text communication, for- warding screen content to learning mates and sending SMS or MMS messages to them.

\section{B. Data collecting means and tool:}

The pre-service teachers used the following means and tools to collect data regarding the participants' learning of mathematics using mobile phones:

Blog: the students were required to comment on and document their mathematics learning using mobile phones. They used a pre-constructed blog in order to suggest ideas regarding the use of mobile phones in the mathematics learning process and to inquire about this use.

The blog started with a welcoming text, written by one of the pre-service teachers who led the experiment. The pre-service teacher informed the students that they could ask questions in the blog, add remarks, add feedback, comment, document events and actions and write about their feelings regarding the experiment. The pre-service teacher also asked the students to write about their expectations and the activities that they would like to be engaged with.

After the first post of the teacher and before the students contributed to the blog, some visitors inquired about the experiment, requesting information about it. In addition, throughout the experiment, several visitors gave remarks and inquired about it in the blog.

Interviews with the students: The pre-service teachers interviewed each participant for thirty minutes about her/his mathematics learning using mobile phones. The interviews were semi structured.

We used the interviews that the pre-service teachers held with the students and the blog in which the students remarked on, documented and discussed their mathematics learning using mobile phones to analyze and characterize the students' perceptions of this learning.

\section{Data processing and analysis}

We used discourse analysis [13] and the grounded theory approach [14] to identify the students' perceptions regarding the mathematics learning using mobile phones.

Ref. [15] describes discourse analysis as an "analysis which studies practices of producing knowledge and meanings in concrete contexts and institutions", and adds: "Discourse analysis systematizes different ways of talking in order to make visible the perspectives and starting points on the basis of which knowledge and meanings are produced in a particular historical moment. It pays attention to the way in which discourses produce and transform social reality, and makes it possible to evaluate the practical consequences of different ways of approaching a particular phenomenon."

We used discourse analysis to analyze the students' writing regarding the way in which they perceived the mathematics learning using mobile phones.

In general, the grounded theory approach has three stages:

- Open coding: Identification of repeated behaviors that can be characterized. This is done by dividing each type of the gathered data into segments and examining these segments for similarity and difference. At this stage, the target is to identify categories of behaviors that occur among the mobile phone mathematics learn- 
ing community. This stage concludes with putting the similar behaviors in the same category and characterizing each category.

- Axial coding: after identifying the categories and characterizing them, we examine the relations among these categories and their subcategories. Here we characterize the behaviors according to the context in which they occur and according to the conditions of their occurrence.

- Selective coding: After refining the categories, subcategories and their characteristics and relations, we try to identify one or two main or core categories that could be used to connect the rest of the categories with them, and to build a conceptual frame of the studied phenomenon: characteristics of the mobile phone mathematics learning community.

We used only the first two stages of the grounded theory to arrive at the various characteristics of the mathematics learning using mobile phones perceived by the students.

\section{FINDINGS}

We used discourse analysis to describe the students' perceptions at the beginning of the experiment and after carrying out some activities. This analysis was based on the students' comments in the blog. Then, we used open and axial coding to categorize the students' perceptions of the mathematics learning qualities and the characteristics of the learning environment when the learning took place in the mobile phone environment. This coding was done based on the students' comments in the blog and in the interviews.

\section{A. Perceptions of the students at the beginning of the experiment}

At the beginning of the experiment, the students perceived various qualities of the mathematics learning using mobile phones as reasons for liking this learning and expecting the success of the experiment. For most of the students, these qualities were equally important for them as reasons to like the learning process and to identify with the experiment. One of the students (let us call her Alaa) was the first to respond to one of the visitors (let us call him Salem) after experiencing the first activity led by the pre-service teacher inside the class:

"Welcome Salem. We thank you for your interest in the experiment.

I'm Alaa from Umelfahem, a member in this experiment and a student in the eighth grade in Elgazali school. A simple description of the experiment: The experiment in which I participate is about learning mathematics using the mobile phone. There are various programs for drawing functions that could be downloaded from the internet to the mobile.

My opinion about this is that I am astonished that we are able to learn mathematics using the mobile phone. I enjoyed this experiment, though we are still at the beginning and though the experiment is a learning one, but we have fun. They also promised us to go in trips so that we discover by ourselves mathematical relations.

We had problems downloading the programs but our overly enthusiasm made us curious and made us want to proceed with the experiment. We downloaded the pro- grams using special cable, and my friend helped me. I operated the graphing programs and liked working with them.

I also had a difficulty writing my remarks in this blog, because I forgot my email, so I had to open a new one.

I will write my remarks in this blog because I am pleased with it."

The first question that could be asked here is: "whom the student is responding to?" To the visitor who requested more information about the experiment, or to the preservice teacher who requested the students to write feedback about their experience in the blog? It seems that when the student started her response she had the visitor in her mind because she approached him by his name. This could be an indicator that the student feels belonging to the experiment, and she is proud to be part of it. She emphasizes initially that she is a member of the experiment, and then she mentions her school. Identifying herself with the experiment is also obvious in her statement "The experiment in which I participate" which came after the first statement "a member in this experiment". She has not felt proud only, but she was also enthusiastic towards proceeding with the experiment in spite of difficulties that she faced at the beginning of it. It seems that the difficulties she faced downloading the programs were forgotten when she started to discover them. This also encouraged her to proceed with the experiment.

Alaa faced difficulties not only when preparing for the experiment but also in writing remarks about it in the blog. This difficulty too does not make her reluctant to write remarks, because she likes the new experience of writing in a blog. Alaa finds herself in a new learning environment with new means of communication, so she gets enthusiastic and wants to experience this new environment fully, despite some difficulties that come in her way. It is not only the novelty of the tools, which she works with that make her enthusiastic, but also other characteristics of the learning environment. One important characteristic that also other students mentioned is going outside the classroom to study mathematics. Alaa has not experienced yet this outdoor learning, for it is a future one; a promised one. Therefore, what made Alaa enthusiastic about her new learning was not only what she experienced already, but also what she was going to experience - something that was promised. Alaa also enjoys the experiment, though she is aware that it is a learning experiment, as if she did not expect that one could enjoy learning. This enjoyment could be another reason why she is enthusiastic about using mobile phones in mathematics leaning, and why she identifies herself with the experiment. Figure 1 is a relational map illustrating this student's perception.

This student perceives the environment of mathematics learning using mobile phones as having different characteristics than the traditional one. These characteristics enrich her learning and make it more enjoyable. Other students had a similar perception, though the characteristics of the experiment considered by them to be beneficial were partially different. For example, one student identified herself with the experiment because it makes learning mathematics easier, simpler, and collaborative.

It should be noted that we consider the novelty of the experiment to be the main reason for the student's astonishment, because many students mentioned this novelty in the blog. 


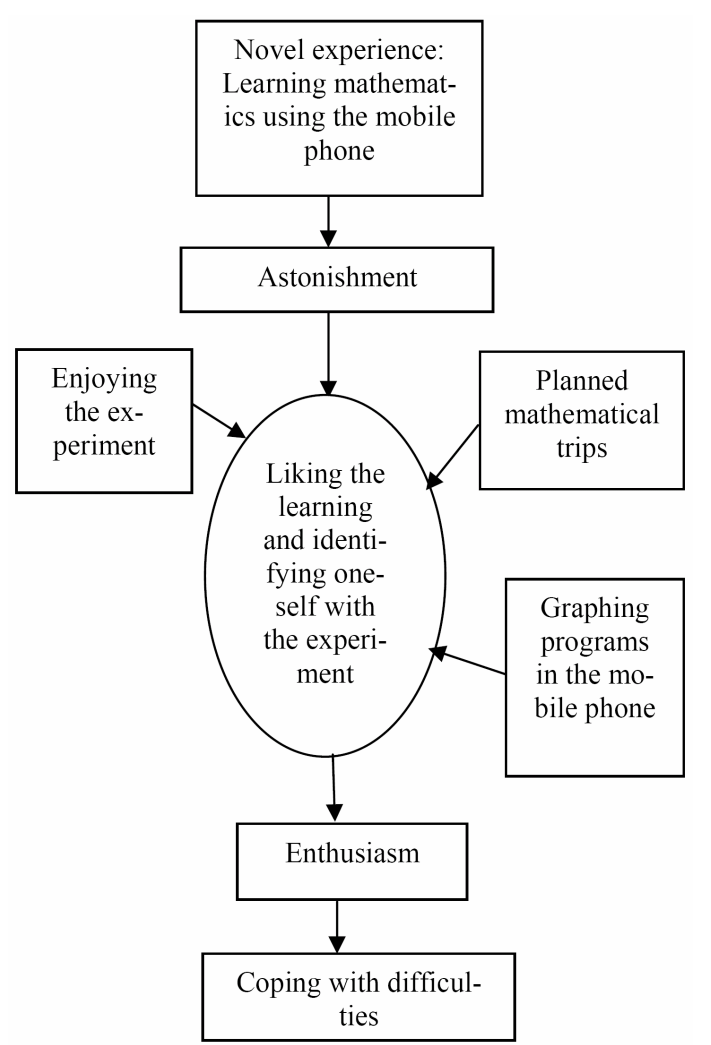

Figure 1. relational map of the student's perception at the beginning of the experiment

\section{B. Perceiving the teacher's characteristics as reasons} for liking the experiment and identifying with it

Other students perceived the characteristics of the preservice teachers and some learning qualities as reasons for liking mathematics learning using mobile phones and identifying with the experiment. One such student, let us call her Sawsan, wrote:

"Hi, my name is Sawsan. I am a student in the eighth grade in Elgazali School, from the town of Umelfahem. I am a member of the experiment too. When the teacher Fatima described the experiment for us, it attracted my attention, because it is strange, because it involves, for the first time, learning mathematics using the mobile phone. I expect that this experiment will succeed because it is new and it is the first time that I hear about it, so we are very eager to do such an experiment. I will be glad if we really learn mathematics through the mobile phone, and graph functions. Fatima encouraged us to participate in the experiment and promised to help us all the way."

Whereas the first student identifies herself with the experiment more than with the school, we see that this student identifies herself with the school more than with the experiment, mentioning first that she belongs to a specific school.

Talking about the experiment, Sawsan mentions only one pre-service teacher of the three managers of the experiment. At the end of the text, she mentions the preservice teacher by her first name only, which a non-formal approach indicating feeling of closeness towards her teacher. We followed the texts of this student in the blog to find out if and how she mentions the same pre-service teacher. We noted that she admires this pre-service teacher, describing her with very nice words: friendly,

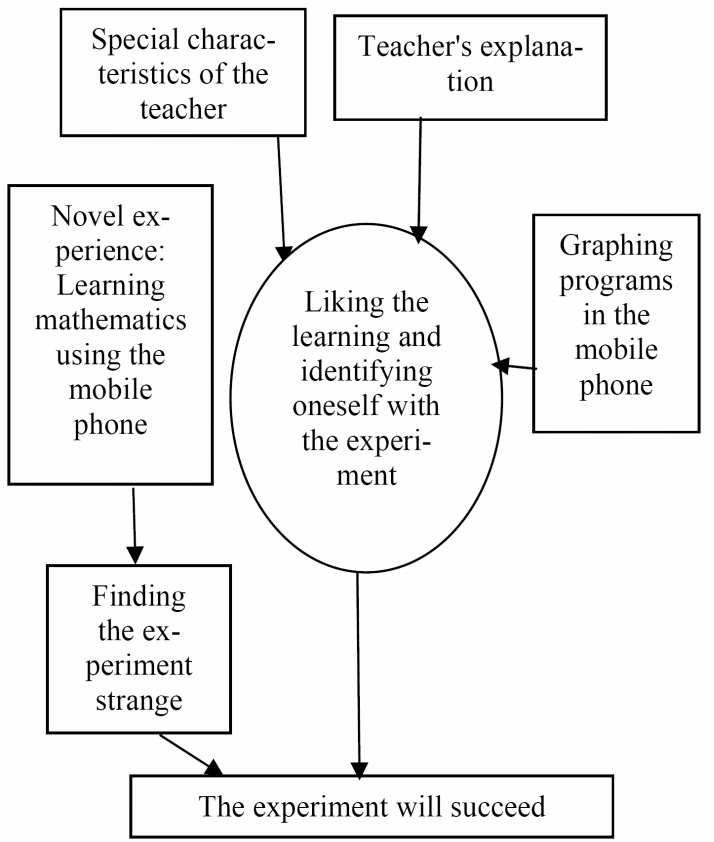

Figure 2. relational map of the teacher's characteristics as influencing the student's perception

charming, smart, and humorous. Therefore, we can say that this student is influenced by some characteristics of the pre-serve teacher. This student thinks also that the novelty of the experiment is sufficient for making the experiment succeed. Figure 2 is a relational map illustrating this student's perception.

This student perceives the experiment through her relation with her teacher. Though she was aware of some experiment characteristics that contributed to her liking and identification with the experiment, such as its novelty and the use of graphing programs, the main reason for her liking and identification was her closeness to the preservice teacher.

\section{Perceptions of the students after experiencing some activities}

Many students perceived the characteristics of the learning environment and qualities of the learning process as reasons for liking mathematics learning using mobile phones and identifying with the experiment. One such student, let us call him Ahmad, wrote:

"At the beginning I hesitated to participate in the experiment because I thought the experiment was a learning one. I was astonished to hear that I would learn mathematics using the mobile phone. At the beginning, I did not conceive this idea because I use the mobile phone for communication, sending messages, hearing music, or playing but not for learning.

I liked the programs that we downloaded from the internet. I explored them by myself, playing with the buttons to discover their functions.

My hopes from the experiment are to spend a good time, to learn new things and to benefit from this experiment. I expect that we will arrive at wonderful things. Today I became confident that the experiment would succeed because we carried out two activities that I was so pleased to carry out. I used the programs in my mobile phone, measured time using it and took pictures. All these 
actions are fun. This is the first time that I learn in a fun environment."

Ahmad hesitated to join the experiment when he thought it is about learning. It seems that he decided to try it for its innovation. He was astonished to know that there is such a thing like learning using the mobile phone.

Ahmad did not expect that mobile phones could be tools for learning. He perceived them as communication and fun tools only. He did not mention having difficulties downloading the programs, operating them and discovering their functions, on the contrary, he reported that he had fun doing so. This enjoyment was even reported by students who had some difficulties downloading the programs at the beginning, but afterwards found them very interesting and easy to operate.

Ahmad agrees with Alaa in his expectations from the experiment. He expects to enjoy it and to learn new interesting and wonderful things. However, more importantly, Ahmad, as many other students, confirms his expectation immediately after the first two experiences. This confirmation comes because of his positive perception of the qualities of the learning process and the features of the mobile phone used in the learning environment. These qualities and features include easy to use programs (midlets), accessibility to his personal mobile phone, interesting and fun features of the mobile phone. These qualities and features made the environment of learning mathematics using mobile phones a fun one. Figure 3 is a relational map illustrating the students' perceptions when they started to carry out mathematical activities using the mobile phone.

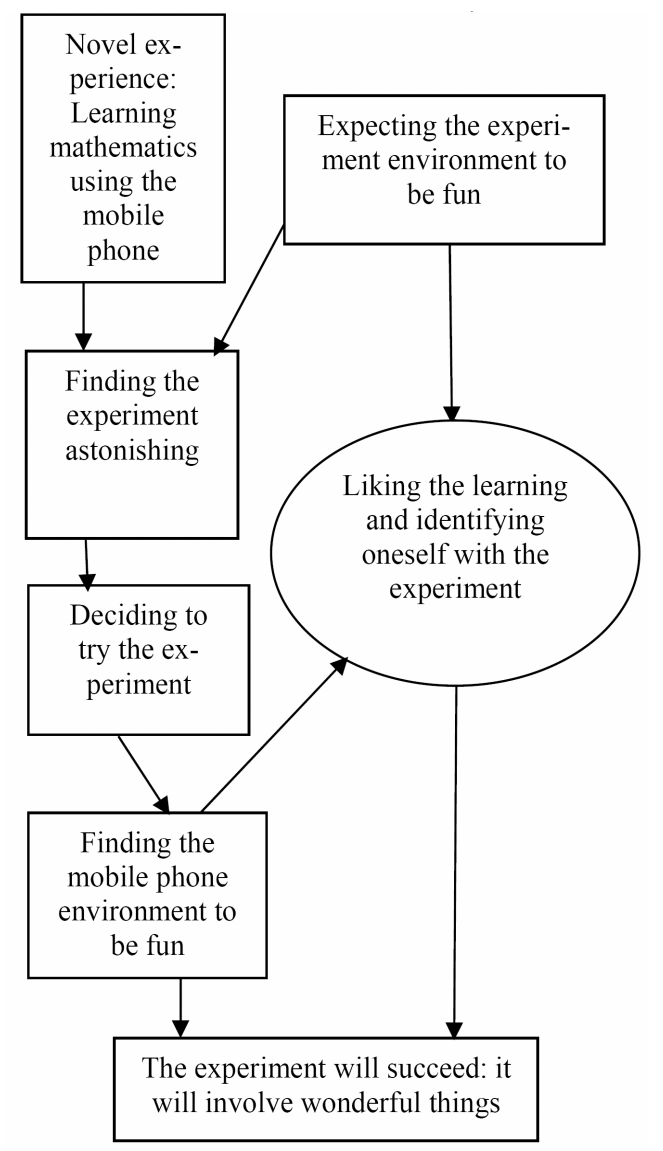

Figure 3. relational map of students' perceptions when they started to carry out mathematical activities using the mobile phone
We can see that the novelty of the experiment is a main factor for the students' participation and involvement. The non-regularity and informality of the experiment made the students curios and consequently they perceived it as strange and astonishing one. It seems that this factor influenced the students' participations and involvement positively. Moreover, the students expected the experiment to be enjoyable and a fun one, and this expectation was realized because of the interesting learning qualities and the mobile phone features. These fun feelings motivated the students making them like the experiment and identify with it, and consequently believe in its success.

\section{Characteristics of the environment of mathematics learning using mobile phones as perceived by the students in the experiment:}

We used open and axial coding to categorize the characteristics of the environment of mathematics learning using mobile phones, which were perceived by the students according to their comments in the blog and in the interviews. We present these characteristics together with selected quotations of the students' comments as evidence for their perceptions.

It introduces novel learning that breaks the routine:

- It makes us break the routine of learning. It is not a learning that is done in the classroom with a chalk and a blackboard.

- It makes us enthusiastic because it is new.

- It makes us use a new technology.

It enables independent learning:

- It enables us to do mathematics alone.

- It enables us to work without the teacher.

- It gives the students an active role over their learning. We decide who does what.

It encourages collaborative learning:

- It encourages collaborative learning.

- It encourages working side by side with our teachers.

- It encourages assisting each other carrying out the activities given to us.

It is a societal and humanistic environment:

- It is a societal experiment: it teaches us patience, competition, initiation and leadership.

- It is a humanistic experiment. It makes the students equal, to the teacher too.

- Working outdoors make us learn and have fun at the same time.

- It makes learning fun because we joke all the time.

- When doing the activities, we felt we belong to the group and want to collaborate to succeed in the activity. When we discussed the results, we felt that all the groups collaborate to explore mathematics together.

It enables exploration of mathematics:

- It enables us to explore mathematics.

- It is interesting to learn the mathematics of our bodies, for example the relation of our weights and heights, the relation between our weights and the time it takes us to go upstairs.

It enables outdoor mathematics: 
- It enables us to explore mathematics in the nature, mathematics of trees and rocks and mathematics of walking.

- It makes learning fun because we learn mathematics in the nature.

- It enables us to do applied mathematics, for example, applying mathematics to describe the movement of a thrown ball.

It enables learning mathematics visually or/and dynamically.

- It involves learning mathematics visually when we use the midlets and see the graphs of functions.

- It involves learning mathematics dynamically with the midlets.

It engages the mathematics student in various mathematical actions:

- It enables us to do various learning actions, like measuring, assigning points, drawing functions, making conjectures and modifying them until we arrive at something that seems reasonable.

- We can do different actions in different activities, for example in one activity I do the measuring, while in another activity I work with the midlet to find the mathematical relation. Sometimes I do two different actions in the same activity.

It makes learning mathematics easy and takes less time:

- Working with midlets to learn mathematics is so easy.

- Learning mathematics with midlets is faster than with paper and pen.

It is important to notice that the success of the experiment was dramatically affected by two main factors: taking the decision to participate in the experiment and actively engaging with carrying out the activities. In the following two tables, we describe the characteristics of the environment of mathematics learning using mobile phones that motivated the students to participate in the experiment, and the qualities of this untraditional mathematics learning that kept them engaged with the experiment, as perceived by the students themselves. These characteristics and qualities were mentioned by the students in the blog and the interviews, and were categorized using open and axial coding of the grounded theory approach. The percentages in the tables were calculated using the number of the students that mentioned a specific characteristic or quality out of the 32 students who participated in the experiment.

We see from table 1 that the novelty of the experiment encouraged half of the students to participate in it, and the use of mobile phones was actually the leading characteristic of the environment that motivated the students to participation in the experiment.

We see from table 2 that what attracted the attention of the students mostly was their ability to learn mathematics outdoors. Moreover, they emphasized their collaboration and the dynamic and visualization that the mobile phones provide, as important qualities of the mathematics learning using mobile phones that kept them engaged with carrying out the activities.
TABLE I.

CHARACTERISTICS OF THE ENVIRONMENT OF THE MATHEMATICS LEARNING USING MOBILE PHONES WHICH MOTIVATED THE STUDENTS TO PARTICIPATE IN THE EXPERIMENT $(\mathrm{N}=32)$

\begin{tabular}{|l|c|}
\hline The characteristic & $\mathbf{\%}$ \\
\hline The novelty of the experiment & 50 \\
\hline The use of the mobile phones in the experiment & 62.5 \\
\hline The strangeness of the experiment & 37.5 \\
\hline The explanations and characteristics of the teachers & 25 \\
\hline The enthusiasm towards the experiment & 37.5 \\
\hline Breaking the routine & 15.63 \\
\hline
\end{tabular}

TABLE II.

QUALITIES OF THE MATHEMATICS LEARNING USING MOBILE PHONES WHICH KEPT THE STUDENTS ENGAGED WITH THE EXPERIMENT $(\mathrm{N}=32)$

\begin{tabular}{|l|c|}
\hline The quality & $\mathbf{\%}$ \\
\hline Independent learning & 15.63 \\
\hline Collaborative learning & 50 \\
\hline Learning in a societal and humanistic environment & 18.75 \\
\hline Learning mathematics through exploration & 15.63 \\
\hline Learning mathematics outdoors & 75 \\
\hline Learning mathematics visually or/and dynamically & 50 \\
\hline $\begin{array}{l}\text { Engaging the mathematics student in various mathe- } \\
\text { matical actions }\end{array}$ & 12.5 \\
\hline Learning mathematics easily and in less time & 43.75 \\
\hline
\end{tabular}

\section{DISCUSSION}

We notice from the findings that most of the students perceived specific characteristics of the environment of the mathematics learning using mobile phones that motivated them to participate in the experiment. The most common perceived characteristics were: Planned outdoors learning of mathematics, planned use of mobile phones in mathematics learning, the characteristics and explanation of the teacher. These special characteristics attracted the students' attention because they were not used to them in the traditional class. These characteristics made the students consider the experiment novel, untraditional and even strange. Consequently, the students got enthusiastic towards the experiment and took the decision to participate in it. Figure 4 shows the relational map of these characteristics.

We see from figure 4 that the basic properties of the experiment which influenced the students' decision to join it are: (1) Outdoors learning of mathematics (2) Use of mobile phones in mathematics learning (3) The characteristics and explanation of the teacher. Moreover, the novelty of the experiment and the use of the mobile phone in mathematics learning were the most mentioned characteristics by the students as influencing their decision to join the experiment. The influence of the novelty of the technology on students' motivation to use it in the learning process is acknowledged in the literature (for example [16]). On the other hand, the use of the mobile phone is perceived through its playful nature when used as a multifunctional device. Ref. [16] pointed that novelty and playful nature of podcasting could be utilized to foster strong pedagogical principles. We can say the same about using mobile phones for learning mathematics. In fact, this is what happened in the experiment itself, where students discovered and described the benefits of exploring mathematics visually and dynamically, and emphasized the fun of doing so authentically and in the nature. 


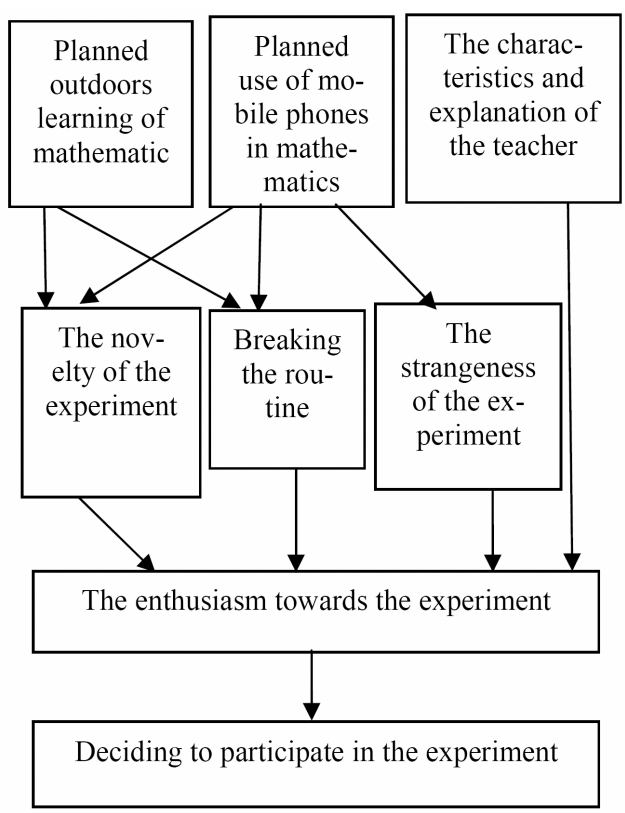

Figure 4. relational map of the factors that influenced the students' decision to participate in the experiment of mathematics learning using mobile phones.

In addition to the playful nature of the mobile phone which made the students enthusiastic to participate in the experiment, another feature of the mobile phone could have influenced the students' enthusiasm: the fact that mobile phones are prohibited in the schools, i.e. prohibited for learning.

Regarding the students' perception of mathematics learning using mobile phones as a result of carrying out the outdoor activities, the students perceived various aspects of their learning experience as presented in table 2 . Below we categorize these various aspects into different categories:

- The relation among the students: is it a relation of equality? Is it a relation of collaboration? Is it a societal relation? Is it a humanistic relation? Etc.

- The relation between the students and the teacher: is it a relation of equality? Is it a relation of dependence? Is it a relation of collaboration? Is it a societal relation? Is it a humanistic relation? Etc.

- The relation between the students and the learning material: how does the student learn it? (Does the student read it from a book? Get it from the teacher? Explore it? Etc.) How does the student represent it? (Visually? Dynamically? Etc.) Where does the student learn it? (Indoors? Outdoors?) How is the learning process? (Easy? Simple? Difficult? Etc.) What actions does the student carry out to learn it?

\section{A. The relation among the students:}

The students liked that they collaborate to learn mathematics and that this collaboration is on equal terms. These equal terms were possible because the students performed different actions in different activities, sometimes different actions in the same activity. Probably this made them value the need of the different actions and that no one of them can be spared. These equal relations were of competitive nature too, as one of the students wrote: "We work in a group. We help each other and collaborate to carry out the activity. We discuss the activity ... every one listens to the other and respects him, even if he was not right. At the same time every one of us has his own mobile phone and uses it to find the mathematical relation. Sometimes we do not graph the right function, so we try again and again. This teaches us patience. Sometimes we get disappointed but we go on and on till we find the right relation and graph. Carrying the activity teaches us to be leaders too. We compete with each other to be the leader of our group; a leader who leads and helps his group". These different opportunities and capabilities, which the mobile phone provided, attracted the attention of the students and probably made them motivated to be actively engaged in the experiment and enthusiastic to explore mathematical relations. These opportunities can also give the students sense of belonging to the learning group [17]. This is actually what happened in this experiment, for example, the students reported their feeling of belonging to the group when carrying out the activities, and to the whole class when discussing the mathematical relations.

\section{B. The relation between the students and the teacher:}

The students were impressed from the fact that the relation between them and their teachers was a social and equal relation. One of the students said: "what impressed me is the collaboration between us and our teachers. We did not consider them as teachers because the environment was that of collaboration and fun". In our opinion, what influenced this relation to be more collaborative and of equal nature is that the mathematical activities were carried out outdoors, i.e. out of the formal order between the teacher and the students in the typical setting of the classroom. We can say that in the mobile phone outdoor setting, the teacher is a facilitator, because facilitating implies equal relations between the teacher and the students [18].

\section{The relation between the students and the learning material:}

The students valued the fact that they explored mathematics and did not learn it only from the teacher. They knew that they could do so, because they used the mobile phone midlets which enable representing mathematics visually and dynamically. This way of representation of mathematical relations helps the learner to feel the dependencies between the mathematical phenomenon parameters or relations [19]. This feeling also makes the arriving at mathematical relations easier and takes less time.

The students were also interested in where they learn the mathematical material, because: (1) they enjoy learning outdoors (2) outdoor learning answers children's natural curiosity and enthusiasm [20] (3) Learning outdoors was a novel experience for them. Furthermore, learning outdoors is learning with fun and learning about real life, about the nature and about oneself. Students are always enthusiastic to learn about themselves and their environment (see for example [21]). Learning with fun encouraged them to learn, bettered their performance and changed the view that some of them had of mathematics as a difficult science. Ref. [22] reported that playing games to learn mathematics provided a less threatening environment for the students than the typical mathematics classroom environment. The unthreatening environment is one reason for the change in how students look at mathe- 
matics. Other reasons for the change in the way students perceive mathematics are related to: (1) the way in which the students learn mathematics, which, in our case, was through exploration (2) the way in which the students represent mathematics, which, in our case, was visually and dynamically (3) the easiness with which the students learn mathematics, which was pointed out by the students in our case. The mobile phone environment provided the students with various opportunities and capabilities that enabled them to perform diversified mathematical actions, thus influencing the way they perceive mathematics.

\section{CONCLUSIONS:}

- The novelty of the experiment and the use of mobile phones in the mathematics learning were the main characteristics perceived by the students as influencing their decision to join the experiment.

- Regarding the students' perception of mathematics learning using mobile phones as a result of carrying out the outdoor activities, the students perceived the following aspects of their learning experience: The relation among the students, the relation between the students and the teacher, and the relation between the student and the learning material. Regarding each aspect the students perceived different characteristics of it.

- The students perceived various qualities of the mathematics learning that were enabled by the use of mobile phones: (1) exploring mathematics independently (2) learning mathematics through collaboration and team work; where the collaboration is on equal terms (3) learning mathematics in a societal and humanistic environment (4) learning mathematics in authentic real life situations (5) visualizing mathematics and investigating it dynamically (6) performing diversified mathematical actions using new and advanced technologies (7) learning mathematics easily and efficiently.

\section{RECOMMENDATIONS}

After experiencing this novel use of mobile phones in mathematics learning, we strongly believe that a lot of opportunities and potentials are yet to be realized. We are still at the beginning of exploring this promising use in the educational environment. In spite of the disruption that these devices could cause in the classrooms, we believe that banning them from schools is not the solution. We should keep studying the pedagogy behind the use of mobile phones in the actual educational environment, and develop appropriate activities that utilize these devices efficiently and profitably in the learning process.

\section{REFERENCES}

[1] Chen J. \& Kinshuk (2005). Mobile Technology in Educational Services. Journal of Educational Multimedia and Hypermedia, 14(1), 91-109.

[2] Rismark, M., Sølvberg, A. M., Strømme, A., and Hokstad, L. M. (2007). Using Mobile Phones to Prepare for University Lectures: Student's Experiences. The Turkish Online Journal of Educational Technology, 6(4). Retrieved August 11, 2008, from http://www.tojet.net/articles/649.htm.

[3] Cobcroft, R., Towers, S., Smith, J. and Bruns, A. (2006). Mobile learning in review: Opportunities and challenges for learners, teachers, and institutions. In Proceedings of Online Learning and Teaching (OLT) Conference 2006, 21-30, Queensland University of Technology, Brisbane. Retrieved May 09, 2008, from https://olt.qut.edu.au/udf/OLT2006/gen/static/papers/Cobcroft_OL T2006 paper.pdf.

[4] Botzer, G. \& Yerushalmy, M. (2007). Mobile Applications for Mobile Learning. Proceedings for "Cognition \& Exploratory Learning in Digital Age" (CELDA), Algrave, Portugal.

[5] Genossar, S.; Botzer, G. \& Yerushalmy, M. (2008). Learning with Mobile Technology: A Case Study with Students in Mathematics Education. Proceedings of the CHAIS conference, Open University. http://telem-pub.openu.ac.il/users/chais/2008/evening/3_2.pdf

[6] Hartwell, C. L. Lightle, S. S. Maxwell, B. (2005). High School Students' Perceptions of Accounting. CPA JOURNAL, 75 (1), 6267. http://www.nysscpa.org/cpajournal/2005/105/essentials/p62.htm

[7] O'Malley J. \& McGraw, H. (1999). Students' perceptions of distance learning, online learning and the traditional classroom. OnLine Journal of Distance Learning Administration, 2 (1). http://www.westga.edu/ distance/omalley24.html.

[8] Eble, K. (1994). Craft of teaching: A guide to mastering the professor's art (2nd edition), New York: Jossey-Bass.

[9] Quitadamo, I.J. \& Brown, A. (2001). Effective teaching styles and instructional design for online learning environments. National Educational Computing Conference, (Chicago, IL). http://confreg.uoregon.edu/NECC2001/program/research_pdf/Quit adamo.pdf.

[10] Duffy, T. M., \& Cunningham, D. J. (1996). Constructivism: Implications for the design and delivery of instruction. In D. H. Jonassen (Ed.), Handbook of research for educational communications and technology. New York: Macmillan.

[11] Silander P, Sutinen E \& Tarhio J (2004). Mobile Collaborative Concept Mapping - Combining Classroom Activity with Simultaneous Field Exploration. In the Proceedings of The 2nd IEEE International Workshop on Wireless and Mobile Technologies In Education, WMTE 2004. pp. 114-118.

[12] Ting, R.Y.-L. (2007). The Advanced Mobile Learning Practices: Learning Features and Implications. In Proceeding of Advanced Learning Technologies, ICALT 2007. Seventh IEEE International Conference, 718 - 720. http://ieeexplore.ieee.org/iel5/4280926/4 280927/04281137.pdf?tp=\&isnumber=\&arnumber $=4281137$.

[13] Wetherell, M. \& Potter, J. (1988). Discourse analysis and the identification of interpretive repertoires. In Charles Antaki (Ed.), Analysing everyday experience: A casebook of methods (pp. 168183). London: Sage.

[14] Strauss, A., \& Corbin, J., 1998, Basics of qualitative research. Thousands Oaks, CA: Sage Publications.

[15] Talja, S. (1999). Analyzing Qualitative Interview Data: The Discourse Analytic Method. Library \& information science research, 21 (4), 459-477 http://www.info.uta.fi/talja/LISR\%5B1\%5D.pdf. (doi:10.1016/S0740-8188(99)00024-9)

[16] Fose, L. \& Mehl, M. (2007). Plugging into Students' Digital DNA: Five Myths Prohibiting Proper Podcasting Pedagogy in the New Classroom Domain. MERLOT Journal of Online Learning and Teaching, 3 (3) http://jolt.merlot.org/vol3no3/mehl.htm.

[17] Hutchinson L., (2003). ABC of learning and teaching in medicine: Educational environment. BMJ , 326, 810-812. http://www.bmj.com/cgi/content/full/326/7393/810. (doi:10.1136/bmj.326.7393.810)

[18] Arnold, R., B.Burke, C.James, D.Martin and B.Thomas. (1991) Educating for Change. Toronto: Between the Lines and the Doris Marshall Institute for Education and Action.

[19] Pesonen M. E., Haapasalo L. \& Ehmke, T. (2006). Critical look at dynamic sketches when learning mathematics. The Teaching of Mathematics, 9 (2), 19-29. http://elib.mi.sanu.ac.yu/files/ journals/tm/17/tm922.pdf.

[20] Cleaver, S. (2007). Classrooms are going green: How Green Classrooms are Reconnecting Kids with Nature. Instructor. http://www2.scholastic.com/browse/article.jsp?id=3748233.

[21] Spencer, N. (2005). Enticing Queensland Teachers and Students with Real Data. http://www.stat.auckland.ac.nz/ iase/publications/ 13/Spencer.pdf.

[22] Bragg, L. (2007). Students' Conflicting Attitudes Towards Games as a Vehicle for Learning Mathematics: AMethodological Dilemma. Mathematics Education Research Journal, 19 (1), 29-44. 


\section{AUTHORS}

Nimer Baya'a is a supervisor of computers, ministry of education, Israel, and a senior lecturer in the computer department in Al-Qasemi, academic college of education, in Baka, Israel (e-mail: bayaan@qsm.ac.il).

Wajeeh Daher is the head of the mathematics department and a senior lecturer in Al-Qasemi academic college of education, Baka, Israel (e-mail: wdaher@macam.ac.il).

This work was supported in part by Al-Qasemi academic college of education and Mofet Institute.

This article was modified from a presentation at the International Conference on Interactive Mobile and Computer Aided Learning (IMCL2009) in Amman, Jordan, April 2009. Submitted, October 25, 2008. Published as resubmitted by the author(s) on July 20, 2009. 